\title{
Uluslararası Kredi Derecelendirme Kuruluşlarının Türkiye İçin Yapmış Oldukları Not Açıklamalarının Hisse Senedi Piyasaları Üzerine Etkisi: BIST 100'de Seçili Sektör Endeksleri Üzerine Uygulama
}

\author{
Serdar KUZU*1 \\ ${ }^{1}$ Asst. Prof., Istanbul University Cerrahpaşa, Vocational School of Social Sciences, Department of the \\ Accounting and Tax Department, Orcid id: 0000-0001-8178-8749
}

Geliş Tarihi/Received: 06.03.2019

Kabul Tarihi/Accepted: 19.03.2019
Doi: dx.doi.org/10.31200/makuubd.536387

Araştırma Makalesi/Research Article

\section{ÖZET}

Son dönemlerde bilgi ve iletişim teknolojilerinde yaşanan gelişmeler ve sermayenin hareketini sınırlayan engellerin ortadan kalkması sonucunda finansal piyasalar arasında ki entegrasyon giderek artmıştır. Yaşanan gelişmeler ülkeleri birbirlerini derinden etkilemiş ve daha bağlantılı hale getirmiştir. Finansal piyasalarda yaşanan gelişmeler ve entegrasyon sayesinde, bireysel ya da kurumsal yatırımcılar, yatırım yapacakları ülkeler hakkında bilgi edinme sorunu ile karşılaşmaya başlamışlardır. Bu noktada yatırımcıların yatırım yapacakları ülke ya da işletme ile ilgili olarak güven sorununu ortadan kaldırmak için kredi derecelendirme kuruluşları ortaya çıkmıştır. Uluslararası kredi derecelendirme kuruluşları, finansal piyasalar arasında fon fazlası ve fon açı̆̆ı olan taraflar arasında bilgi asimetrisi sorununu minimize etmeyi amaçlayan kuruluşlardır. Uluslararası kredi derecelendirme kuruluşları ülkelerin kredi riskini ortaya koyan bir başka ifadeyle finansal yükümlülüklerin karşılanabilme yeteneğini ve işletmelerin finansal profilini ortaya koyan kuruluşlar olarak görülmektedir $\mathrm{Bu}$ açıdan değerlendirildiğinde ülkelerin ilgili kuruluşlarca belirlenen kredi derecelendirme notları, ilgili ülkenin uluslararası piyasalara erişimine, borçlanma maliyetlerine, potansiyel yatırımcı kapasitesinin artması gibi bir takım parametreler üzerinde etkili olduğu gözlemlenmektedir. Bu açıdan ele alındığında S\&P, Moody’s ve Fitch'in 20022018 yılları arasında Türkiye için vermiş oldukları kredi not açıklamaları sonrasında BIST 100 de yer alan seçili sektörler üzerinde etkisinin olup olmadığı olay çalışması metodu yardımıla incelenecektir.

Anahtar kelimeler: Uluslararası Kredi Derecelendirme Kuruluşları, Olay Çalışması Metodu, Anormal Getiri.

* Sorumlu yazar/Corresponding author

E-mail/e-ileti: serdar.kuzu@istanbul.edu.tr 
Kuzu, $S$.

\section{The Impact of International Credit Rating Agencies Notes on The Stock Markets of Turkey: Application on Selected Sector Indices in BIST 100}

\section{ABSTRACT}

With the recent developments in information and communication technologies and the elimination of barriers limiting the movement of capital, the integration between financial markets has gradually increased as financial markets have been reached all over the world at the same time. Developments have deeply affected and linked countries to each other. Thanks to the developments in financial markets and integration, all investors, either individual or institutional, have trouble getting information about the countries they will invest in. At this point, credit rating agencies have emerged in order to eliminate the problem of trust regarding the investors' country or business. International credit rating agencies are aiming to minimize the problem of information asymmetry between the financial markets and the surplus and fund deficit parties. International credit rating agencies can be considered as an indicator of the ability of the country to meet the financial liabilities and, in other words, the credit risk of the countries. When evaluated in this respect, it is observed that the countries' credit rating grades are effective on the access to international markets, borrowing costs, and potential investor capacity. From this point of dealt with the S \& P, Moody's and Fitch's 2002-2018 between the years will be examined using the event study methodology to be BIST 100 also after credit rating descriptions which have been given to Turkey is the impact on selected sectors concerned is located.

Keywords: International Credit Rating Agencies, Event Study Method, Abnormal Return.

\section{GíRiş}

Elektro 19.yy itibaren uluslararası kredi derecelendirme kuruluşları finansal piyasalar içerisinde yer almaya başlamıştır. Özellikle 1980 yıllarından itibaren gelişmekte olan ülkelerde tasarruf olanaklarında yaşadıkları sıkıntılar ve ekonomik büyüme için gerekli olan fonların sağlanamaması nedeniyle devlet iç borçlanma senetleri ile yabancı sermayeyi ülkelerine çekme çabası içinde olmuşlardır. $\mathrm{Bu}$ durum uluslararası kredi derecelendirme kuruluşlarının bu husus üzerinde odaklanmalarına neden olmuştur. İlgili kuruluşların faaliyetlerinin sürdürmelerinde ana nedenlerden biri bilgi asimetrisi sorununu ortadan kaldırmaktır. Bilgi asimetrisi (information asymmetry) işletme dışında yer alan çıkar grupları ile işletme yöneticilerinin sahip oldukları bilgi ile bilgiye ulaşabilme konusundaki farklılığa dayanır. İşletmeyle ilgili bilgiyle daha donanımlı olan işletme yöneticileri ile yeterli bilgiye 
sahip olmayan işletme dışında ki gruplar (hissedar, borç sahipleri) arasındaki bilgi farkı bilgi asimetrisi olarak ifade edilmektedir (Megginson vd., 1997). Bunun yanında ülkelerin kredi risklerini ölçerek, ülkelerin ya da kuruluşların borçlanma olanaklarını rahatlatmalarına olanak sağlamaktadır. İlgili çalışmalar çerçevesinde kredi kuruluşlarının verdiği bilgilerin sermayenin yönünü belirlemede önemli rol oynadığı, bir bakıma sinyal etkisi taşıdığ görülmüştür. Ülkelerin ya da işletmelerin sermaye yapısı ile ilgili olarak kararları değiştikçe çıkar gruplarınında ülke/işletme ile ilgili olarak beklentileride değişmektedir. $\mathrm{Bu}$ noktada ülke/işletme yöneticileri ülkelerin sermaye yapısında yapacakları değişikliklerle, ülke/işletme dışındaki çıkar gruplarına ülkenin/işletmenin geleceği ile ilgili mesajlar göndermektedirler. Finans literatüründe bu "sinyal yaklaşımı" olarak ifade edilmektedir. Bunun yanında Levine (1996), yaptığı çalışmada hisse senedi getirisi ile ülke ekonomik büyümeleri arasında pozitif bir ilişki bulmuştur. Bu durum ülkelere verilen kredi derecelendirme notu ile hisse senedi piyasası arasında direkt ilişkili olduğu sonucunu ortaya çıkarmaktadır (Iltas vd., 2017).

Kredi derecelendirme notu, ilgili değerlendirme kuruluşun, ilgili işletmenin, menkul kıymetin ya da yükümlülügün belirli tarih itibarıyla kredi itibarının görüşünü ortaya koyan bir göstergedir. SPK tarafından kredi derecelendirmesi; "İşletmelerin risk durumları ve ödeyebilirliklerinin veya borçluluğu temsil eden sermaye piyasası araçlarının anapara, faiz ve benzeri yükümlülüklerinin vadelerinde karşılanabilirliğinin derecelendirme kuruluşları tarafından bağımsız, tarafsız ve adil olarak değerlendirilmesi ve sınıflandırılması faaliyeti““ olarak tanımlanmıştır.

Tablo 1. NRSRO statüsündeki kredi derecelendirme kuruluşlarının kredi değerlendirmeleri

\begin{tabular}{|l|c|c|c|c|c|c|}
\hline & $\begin{array}{c}\text { Finans } \\
\text { kurumları }\end{array}$ & $\begin{array}{c}\text { Sigorta } \\
\text { Şirketleri }\end{array}$ & $\begin{array}{c}\text { Kurumsal } \\
\text { İhraççılar }\end{array}$ & $\begin{array}{c}\text { Varlığa } \\
\text { Dayalı } \\
\text { Kıymetler }\end{array}$ & $\begin{array}{c}\text { Devlet } \\
\text { Borçlanma } \\
\text { Senetleri }\end{array}$ & Toplam \\
\hline A.M. Best & $\mathrm{N} / \mathrm{R}$ & 7,191 & 1,079 & 5 & $\mathrm{~N} / \mathrm{R}$ & 8,275 \\
\hline DBRS & 12,73 & 164 & 2,938 & 14,951 & 18,865 & 49,648 \\
\hline EJR N/R & 9,446 & 864 & 6,42 & $\mathrm{~N} / \mathrm{R}$ & $\mathrm{N} / \mathrm{R}$ & 16,73 \\
\hline Fitch & 39,189 & 3,261 & 18,933 & 29,108 & 205,674 & 296,165 \\
\hline HR Ratings & 560 & $\mathrm{~N} / \mathrm{R}$ & 184 & $\mathrm{~N} / \mathrm{R}$ & 374 & 1,118 \\
\hline JCR & 839 & 59 & 2,464 & $\mathrm{~N} / \mathrm{R}$ & 440 & 3,802 \\
\hline KBRA & 838 & 32 & 0 & 8,11 & 72 & 9,052 \\
\hline Moody's & 36,631 & 2,484 & 28,635 & 59,32 & 598,614 & 725,684 \\
\hline Morningstar & 44 & $\mathrm{~N} / \mathrm{R}$ & 297 & 2,53 & $\mathrm{~N} / \mathrm{R}$ & 2,871 \\
\hline S\&P & 57,091 & 6,496 & 51,213 & 43,76 & $\mathrm{~N} / \mathrm{R}$ & 2,871 \\
\hline TOTAL & 157,638 & 20,551 & 112,163 & 157,784 & $1,744,345$ & $2,192,211$ \\
\hline
\end{tabular}

Kaynak: (SEC, December 2018) 
Kuzu, $S$.

Tablo 2. NRSRO statüsündeki kuruluşların gelir dağılımı

\begin{tabular}{|l|c|c|c|c|c|c|}
\hline$(\%)$ & $\mathbf{2 0 1 2}$ & $\mathbf{2 0 1 3}$ & $\mathbf{2 0 1 4}$ & $\mathbf{2 0 1 5}$ & $\mathbf{2 0 1 6}$ & $\mathbf{2 0 1 7}$ \\
\hline Moody's \&Fitch ve S\&P & 94,7 & 94,5 & 94,3 & 93,7 & 94,4 & 95,8 \\
\hline Diğer NRSRO statüsündeki kuruluşlar & 5,3 & 5,5 & 5,7 & 6,8 & 5,6 & 4,2 \\
\hline TOPLAM & 100 & 100 & 100 & 100 & 100 & 100 \\
\hline
\end{tabular}

Kaynak: Annual report on nationally recognized statistical rating organizations, Aralık 2017.

Önde gelen üç kuruluştan olan Moody's \&Fitch ve S\&P sektördeki toplam payı 2017 yılsonu itibariyle \%95,8 seviyesindedir. Bu kuruluşların tarihsel gelişimine bakıldığında 1900'lü yılların başına dayansa da ana faaliyetlerini 1970'li yıllardan itibaren göstermeye başlamışlardır. S\&P, 1970 li yıllarda kamu ve özel borç ihraççılarına, borçlanma enstrümanlarına derecelendirme notu vermek için hizmet vermeye başlamıştır. Bunun yanında S\&P kredi derecelendirmesinde ekonomik durum yanında ülkelerin siyasi riskleri, Merkez Bankalarının bağımsızlığı, demokrasi, seçim sistemi ve ülkelerin dış politika gelişmelerini dikkate almaktadır. 1900'lü yıllarında kurulan Moody’s şirketi ilk değerlemesini 1909 yılında yapmış olup kredi değerleme açısından Moody’s ile S\&P arasında notların ifade ettiği anlam açısından çok büyük bir farklılık yer almamaktadır. Farklılık sadece sembol açısından yer almaktadır. Fitch Ratings 1913 yılında John Knowles Fitch tarafından Fitch Publishing Company adı ile kurulmuş olup 1975 yılında SEC tarafından NRSRO statüsü tanınan üç kredi derecelendirme kuruluşundan biri olmuştur. (Fitch Ratings, 2012).

Tablo 3. Kredi derecelendirme kuruluşları not sistemi

\begin{tabular}{|c|c|c|c|c|}
\hline S\&P & Fitch Ratings & Moody's & Not'un Açıklaması & \\
\hline AAA & AAA & Aaа & En Yüksek Derece & \multirow{10}{*}{$\begin{array}{c}\text { Yatırım Yapılabilir } \\
\text { Seviye }\end{array}$} \\
\hline $\mathrm{AA}+$ & $\mathrm{AA}+$ & Aa1 & \multirow{3}{*}{ İyi Kredi Derecesi } & \\
\hline $\mathrm{AA}$ & AA & $\mathrm{Aa} 2$ & & \\
\hline AA- & AA- & Aa3 & & \\
\hline $\mathrm{A}+$ & $\mathrm{A}+$ & $\mathrm{A} 1$ & \multirow{3}{*}{ İyi Kredi Derecesi } & \\
\hline $\mathrm{A}$ & $\mathrm{A}$ & $\mathrm{A} 2$ & & \\
\hline A- & A- & A3 & & \\
\hline $\mathrm{BBB}+$ & $\mathrm{BBB}+$ & Baa1 & \multirow{3}{*}{ Ortanın Altı Seviye } & \\
\hline $\mathrm{BBB}$ & $\mathrm{BBB}$ & Baa2 & & \\
\hline BBB- & BBB- & Baa3 & & \\
\hline $\mathrm{BB}+$ & $\mathrm{BB}+$ & Ba1 & \multirow{2}{*}{ Yatırım Yapılmaz } & \multirow{9}{*}{ Spekülatif Seviye } \\
\hline $\mathrm{BB}$ & $\mathrm{BB}$ & $\mathrm{Ba} 2$ & & \\
\hline BB- & BB- & $\mathrm{Ba} 3$ & \multirow{2}{*}{ Spekülatif } & \\
\hline $\mathrm{B}+$ & $\mathrm{B}+$ & B1 & & \\
\hline $\mathrm{B}$ & $\mathrm{B}$ & B2 & \multirow{2}{*}{$\begin{array}{l}\text { Önemli Derecede } \\
\text { Spekülatif }\end{array}$} & \\
\hline B- & B- & B3 & & \\
\hline $\mathrm{CCC}+$ & $\mathrm{CCC}$ & $\mathrm{Caa}$ & \multirow{2}{*}{ Şiddetli Riskli } & \\
\hline $\mathrm{CCC}$ & $\mathrm{CC}$ & Caaa3 & & \\
\hline $\mathrm{CC}$ & $\mathrm{C}$ & $\mathrm{C}$ & Aşırı Spekülatif & \\
\hline \multirow{3}{*}{$\mathrm{D}$} & DDD & \multirow{3}{*}{$\mathrm{C}$} & \multirow{3}{*}{$\begin{array}{l}\text { Yükümlülüğünü } \\
\text { Yerine Getiremez }\end{array}$} & \multirow{3}{*}{ Default } \\
\hline & DD & & & \\
\hline & $\mathrm{D}$ & & & \\
\hline
\end{tabular}

Kaynak: (Kronwald, 2009) 
Kredi derecelendirme notları özellikle fon ihtiyacı olanları uluslararası piyasalara girme konusunda önemli etkiye sahiptir. Burada önemli olan hususlardan biride ölçülebilen kriterlerin yanında ölçülemeyen (kalitatif) kriterlerin de dikkate alınması hususudur. Bu durum özellikle 21.yy başlarında etkili olması sebebiyle değerlendirme notu ile değerlendirmeye esas kriterler arasında ki ilişsinin ortaya komasını güçleştirmiştir. Bunun yanında değerlendirmenin Kişi başına düşen milli gelir, Gayri safi yurtiçi hâsıla (GSYH) büyümesi, Enflasyon, mali denge, Dış borç, dış denge, Ekonomik gelişmişlik seviyesi, Temerrüde düşme geçmişi, siyasi risk ve ekonomik serbestlik endeksi gibi bir takım yöntemlerinde yer aldığı parametreler kullanılarak yapılması ve bu paramtrelerin fazlalığı ve değerlendirme kuruluşlarının her bir kritere verilen ağırlığın tam olarak bilinememesi ilişkinin ortaya konmasını zorlaştırmaktadır.

Kredi derecelendirme kuruluşlarının Türkiye sürecine bakıldığında, Türkiye için ilk kez Moody’s 1992 yılında yapmıştır. (Ovalı, 2014). 1992 tarihinde ülke notunu yatırım yapılabilir seviye olan Baa3 olarak belirlemiştir. Moody's ten sonra Tükiye'nin kredi notunu belirleyen ikinci kuruluş S\&P olup 1993 tarihinde S\&P ülke notunu BBB seviyesinde olduğunu ifade etmiştir. Fitch ise Tükiye'nin kredi notunu 1994 yılında vermeye başlamış olup ilk ülke notunu spekülatif statüde B seviyesinde açıklamıştır.

Tablo 4. Yıllar itibarıyla türkiye'nin ülke notu gelişimi

\begin{tabular}{|c|c|c|c|c|c|}
\hline Tarih & $\begin{array}{c}\text { Moodys } \\
\text { Not-Görünüm }\end{array}$ & Tarih & $\begin{array}{c}\text { S\&P } \\
\text { Not-Görünüm }\end{array}$ & Tarih & $\begin{array}{c}\text { Fitch } \\
\text { Not-Görünüm }\end{array}$ \\
\hline 21.12 .2000 & B1 Pozitif & 08.03 .2004 & B+ Pozitif & 02.08 .2001 & B Negatif \\
\hline 06.04 .2001 & B1 Negatif & 17.08 .2004 & BB- Durağan & 05.02 .2002 & B Negatif \\
\hline 15.01 .2002 & B1 Durağan & 23.01 .2006 & BB- Pozitif & 25.03 .2002 & B- Negatif \\
\hline 10.07 .2002 & B1 Negatif & 27.06 .2006 & BB- Durağan & 06.08 .2003 & B Pozitif \\
\hline 21.10 .2003 & B1 Durağan & 03.04 .2008 & BB- Negatif & 25.09 .2003 & B Pozitif \\
\hline 11.02 .2005 & B1 Pozitif & 31.07 .2008 & BB- Durağan & 09.02 .2004 & B+ Durağan \\
\hline 14.12 .2005 & Ba3 Durağan & 13.11 .2008 & BB- Negatif & 25.08 .2004 & B+ Pozitif \\
\hline 18.09 .2009 & Ba3 Pozitif & 17.09 .2009 & BB- Durağan & 13.01 .2005 & BB-Durağan \\
\hline 08.01 .2010 & Ba2 Durağan & 17.09 .2009 & BB- Durağan & 06.12 .2005 & BB-Pozitif \\
\hline 05.10 .2010 & Ba2 Pozitif & 09.02 .2010 & BB Pozitif & 10.05 .2007 & BB-Durağan \\
\hline 20.06 .2012 & Ba1 Pozitif & 01.05 .2012 & BB Durağan & 03.12 .2009 & BB+Durağan \\
\hline 16.05 .2013 & Baa3 Durağan & 27.03 .2013 & BB+ Durağan & 24.11 .2010 & BB+Pozitif \\
\hline 11.04 .2014 & Baa3 Negatif & 07.02 .2014 & BB+ Negatif & 23.11 .2011 & BB+Durağan \\
\hline 18.07 .2016 & Baa3 Negatif & 20.07 .2016 & BB u & 05.11 .2012 & BBB-Durağan \\
\hline 23.09 .2016 & Ba1 Durağan & 01.05 .2018 & BB-u & 04.04 .2014 & BBB- Durağan \\
\hline 07.03 .2018 & Ba2 Durağan & 17.08 .2018 & B+ Durağan & 27.01 .2017 & BB+ Durağan \\
\hline 01.06 .2018 & Ba2 Negatif & & & 13.07 .2018 & BB- Negatif \\
\hline 17.08 .2018 & Ba3 Durağan & & & & \\
\hline Kaynak: & & & & \\
\hline
\end{tabular}

Kaynak: (S\&P, 2019) (Moody's, 2019) (Fitch, 2019) 
Kuzu, $S$.

Yukarıda Tablo 3'te Yıllar İtibarıyla Türkiye'nin Ülke Notu Gelişimi verilmiş olup çalışmada kredi derecelendirme kuruluşlarının Türkiye hakkında ki verdikleri not sonrasında BIST 100 VE BIST 100 de yer alan çeşitli sektörler üzerinde etkisini incelenecektir. Çalışmada amaç çalışmada kredi derecelendirme kuruluşlarının Türkiye hakkında açıkladıkları notların endeks üzerinde etkisinin olup olmadığını ortaya koymaktır.

\section{LITERATÜR TARAMASI}

Bir ülkede kalkınma ve yatırım ypılabiir ülke statüsünü kazanmak için çeşitli faktörlerin sağlanması gerekmektedir. Çalışmamızda Türkiye hakkında ki not veren Fitch’e baktığımızda daha önce yatırım yapılabilir ülke statüsünü kazanması aşamasında dikkate aldığı faktörler; Türkiye'nin dengeli bir şekilde inişe geçerken kısa vadeli makro boyutta finansal risklerin azalması, tasarruf önlemleri ve gerileyen devlet borçlarının kredi kanallarına aktarılması, güçlü bankacılık sistemi, olumlu büyüme görünümü ve kaynak çeşitliliğine giden ekonomi gibi faktörler yer almaktadır. (Parker ve Rawkins, 2012: 1-3);

Moodys' Türkiye için yatırım yapılabilir ülke statüsünü kazanması aşamasında dikkate aldığg faktörler ise cari açık, kısa vadeli dış borcun döviz rezervlerine oranı, dış dengesizlikleri, siyasi riskler, kurumsal ve yapısal reformları (Bireysel emeklilik sistemi ve enerji verimliliği gibi) ve sıkı mali disiplin sonucu tüm makroekonomik göstergelerdeki iyileşme ve borç seviyesinin GSYH'ye oranı gibi faktörleri ele almaktadır. (Dünya Gazetesi, 2013).

S\&P'nin Türkiye için yatırım yapılabilir ülke statüsünü kazanması aşamasında dikkate aldığg faktörler ise ihracatın performası, yabancı para cinsi borçlanmayı sınırlayan politikalar, nominal kredi büyümesini sınırlayan önlemler, siyasi riskler, mali disiplin, maliye ve para politikası seçimlerden bağımsız yürütülmesi, Türkiye ekonomisinin dış kaldıracı, borçlanma ve hisse senedi piyasalarına giriş ve çıkışlar gibi faktörleri ele almaktadır.

Cantor ve Packer (1996), S\&P ve Moody’s kredi derecelendirme kuruluşlarının, kredi derecelendirme notunda ekili olduğu düşündüğü Kişi başına düşen milli gelir, Gayri safi yurtiçi hâsıla (GSYH), Enflasyon, Mali denge, Dış denge, Dış borç, Ekonomik gelişmişlik seviyesi ve Temerrüde düşme geçmişi gibi sekiz makroekonomik göstergenin ile ülkelerin borç ödeme yeteneği ile ilişkisini ortaya koymuşlardır. Çalışmada ilişki Olağan En Küçük Kareler (OLS) yöntemi ortaya konmaya çalışılmış ve çalışma sonucunda bu makroekonomik 
göstergelerin ilgili ülkeye verilen notlar arasında ilişki derecesi \%90 üzerinde bir oranda çıkmıştır (Cantor ve Packer, 1996).

Haque vd. (1998), yaptıkları çalışmada ilgili ülkenin kredi notunda etkili olduğu makro ekonomik parametrelerin ve politikaların ilişkisini ele almışlardır. Çalışma sonucunda politika değişkenlerinin ilgili ülkenin borç ödeme yeteneğini sadece, bu kapasitenin önem arz ettiği zamanlarda etkili olduğu sonucuna ulaşmışlardır. Bunun yanında politik bir risk sonucunda bu durumun makro ekonomik göstergelere yansıyacağını ifade etmişlerdir. (Haque vd., 1998)

Jüttner ve Carthy (2000), Cantor-Packer'ın yaptıkları çalışmayı ele alarak, bu modelin 1997 Asya krizinden sonra modelin açıklama seviyesinin düştüğünü ifade etmişlerdir. Çalışmada Cantor-Packer'ın ele aldığı sekiz makroekonomik göstergenin yanında; bono faizi ile kısa vadeli faiz farkı, banka bilançosunda yer alan problemli varlıkların GSYİH içindeki payı, finansal sektörün belirli koşula bağlanmış yükümlülüklerin GSYİH içindeki payı, Özel sektörün kredi büyümesinin GSYİH içindeki payı ve reel efektif kur ortalaması olmak üzere beş adet makroekonomik göstergeninde dikkate alınması gerektiğini ifade etmişlerdir. Çalışma sonucunda enflasyonun temerrüde düşme olasılığında etkili olduğu ve önerdikleri beş adet göstergeden sadece bono faizi ile kısa vadeli faiz fark1 ve reel efektif kur ortalamasının istatistiki olarak anlamlı çıktığı görülmüştür. (Juttner ve Carthy, 1998)

Reisen (2003), Jüttner ve Carthy yaptıkları çalışmayı ele alarak yaptığı değerlendirmede kredi derecelendirme kuruluşlarının ilgili ülke için verdikleri notlar arasında ilişki ortaya koyabilecek herhangi bir parametre ya da modelin bulunmadığını ifade etmiştir (Reisen, 2003).

Monfort ve Mulder (2000), 1994-1999 yılları arasında 20 gelişmekte olan ülkenin notlarını ele alarak yaptıkları çalışmada kredi derecelendirme notlarını ortaya koyan kısa ve orta vadeli parametrelerin neler olduğunu belirlemek amacıyla Hata Düzeltme Modelini (ECM) kullanmışlardır. Çalışmada Cantor ve Packer'in belirledikleri sekiz adet parametrenin açıklayıcılık derecesinin 1997 Asya krizi ile birlikte azaldığı ve dış borcun ihracata oranı, ihracat büyümenin GSYH içindeki payı ve enflasyonun kredi derecelendirme notu üzerinde etkili olduğu sonucuna ulaşmışlardır. Buna karşın kredi derecelendirme kuruluşlarının verdikleri notların kriz zamanlarında, gereken zamanda gecikmeli sinyaller verdiklerini ifade etmişlerdir (Monfort ve Mulder, 2000). 
Kuzu, $S$.

Mulder ve Perelli (2001) yıllarında 1992-1999 dönemlerinde,25 gelişmekte olan ülkenin kredi notlarının belirlenmesinde etkili olan parametreleri ele aldıkları çalışmada Havuzlanmış Olağan En Küçük Kareler ve Uygun Genelleştirilmiş En Küçük Kareler istatistiki yöntemlerini kullanmışlardır. Çalışma sonucunda kredi notunu belirlemede en etkili parametrenin yapılan yatırımın GSYH içindeki payı olduğunu bunun yanında dış borcun ihracata içindeki payı ve temerrüde düşme geçmişi not üzerinde etkili olduğu sonucuna ulaşmışlardır. Bunun yanında ayrıca 1997 Asya krizi gibi yapısal kırılmaların not değerlendirmeleri üzerinde görüşleri değiştirdiğini gözlemlenmiştir (Mulder ve Perrelli, 2001).

Afonso vd. (2011) 2006 yılında kredi derecelendirme notlarını ortaya koyan kısa ve uzun vadeli parametrelerin neler olduğunu belirlemek amacıyla çalışma yapmışlardır. Çalışmada vade ayrımına gidilmesinde ki amaç politika yapıcılarına hangi dönemde hangi parametreye önem vermeleri hususu olduklarını ifade etmişlerdir. Çalışma sonucunda kullanılan parametreler sonucunda oluşturulan modelin kredi notunu belirleme tahmininin \%50 ye yakın oranda çıktığı gözlemlenmiştir. Bunun yanında tahmin edilen not ile duyrulan not arasında sadece bir kademe fark olduğu gözlemlenmiştir (Afonso vd., 2011).

Alsakka ve Gwilym (2010), 2000-2008 dönemi gelişmekte olan ülkelerin kredi notlarını belirlemeden etkili olan parametrelerin neler olduğunu ortaya koymak için 17 adet makroekonomik göstergeyi ele alarak çalışma yapmışlardır. Çalışmada altı kredi derecelendirme kuruluşunun notları değerlendirilmiş olup, çalışma sonucunda kredi notunun belirlenmesinde birçok finansal ve makroekonomik göstergenin önemli rol oynadığ 1 fakat hangi kredi derecelendirme kuruluşunun bu parametrelere ne kadar ağırlık verdiklerini bilinmediğinden dolayı metodolojilerinin farklılık arz ettiği görülmüştür. Bir başka deyişle kredi notlarının belirlenmesinde etkili olan parametrelerin her bir kuruluş için farklılık oluşturmakta ve ülkelerin not revizyonunda etkili olan parametrelerin kuruluş bazında farkl11ık arz ettiği gözlemlenmiştir (Alsakka ve Gwilym, 2010).

Şensoy vd. (2016), 2000-2015 dönemlerinde Fitch ve Moody's kredi derecelendirme kuruluşlarının 11 gelişmekte olan ülke için vermiş oldukları notların, ilgili ülke borsaları üzerinde etkili olup olmadığını ortaya koymaya çalışmışlardır. Çalışma sonucunda kredi derecelendirme kuruluşlarının açıkladıkları not zamanlarının borsalar üzerinde karşılıklı olarak istatistiki olarak bir ilişkinin mevcudiyeti görülmemiştir (Şensoy vd., 2016). 
Habib vd. (2016), 2008-2014 dönemleri arasında kredi derecelendirme kuruluşlarının Pakistan hakkında yaptıkları not güncellemelerinin Karachi borsasında yer alan 22 banka üzerinde etkisini incelemişlerdir. Çalışmada olay çalışması yöntemi (event study method) kullanılmış olup çalışma sonucunda not değişimlerinin aşağı yönde revize edildiği zamanlarda banka hisse fiyatlarına pozitif yansıdığı görümüştür (Habib vd., 2016).

Yüksel ve Özsarı (2017) 1992-2015 dönemleri arasında sekiz adet değişken ile Türkiye'nin Kredi Notu arasında ki ilişkiyi ortaya koymak için yaptıkları çalışmada MARS Yöntemini kullanmışlardır. Çalışma sonucunda sadece cari açık ile kredi notu arasında bir ilişkinin mevcut olduğunu ifade etmişlerdir (Yüksel ve Özsarı, 2017).

Y1ldırım vd. (2018), 2012-2016 dönemleri arasında uluslararası kredi derecelendirme kuruluşlarından S\&P, Fitch ve Moody's not durum açıklamalarının BIST 100'de yer alan XBANK, XUSIN, XUMAL, XKOBI, XTCRT, XULAS, XMADN, XMANA ve XYORT sektörleri üzerinde etkisini ele alan çalışma yapmışlardır. Çalışma sonucunda kredi derecelendirme kuruluşlarının not açıklamalarının BIST 100 de yer alan sektörler üzerinde etkisinin kısıtlı olduğu gözlemlenmiştir (Yıldırım vd., 2018).

\section{VERİ SETİ VE METODOLOJI}

Çalışmanın amacı kredi derecelendirme kuruluşlarından S\&P, Moody's ve Fitch'in Türkiye için yıllar itibarıyla verdikleri kredi notlarının BIST 100 de yer alan ve BIST 100 lokomotifi sayılacak Banka, Mali, Kobi, Ticari, Yatırım Ortaklığı, Bilişim, Ulaştırma ve Sınai endeksleri üzerinde etkisi olay çalışması yöntemi (event study method) ile ortaya konmaya çalışılmıştır. Bilindiği üzere kredi derecelendirme kuruluşlarının verdikleri notlar finansal piyasalar üzerinde etki yaratmakta ve bundan dolayı not revizyonlarında etkilenme derecesi yüksek olacağı öngörülen sektörlere ilişkin endekslere yer verilmiştir.

Çalışmada kullanılan etkisi olay çalışması yöntemi finans literatüründe yapılan çalışmalarda sıklıkla kullanılan bir yöntem olup ilk defa 1933 yılında Dolley tarafından hisse senedi bölümlendirmesinin hisse senetleri üzerinde etkisini ortaya koymak amaciyla geliştirilmiştir. Bu model uygulamasın da izlenecek birkaç adımlar yer almaktadır. Tahmin penceresi (Estimation Window) kısmında fiyat hareketlerinin tanımlanmasında, varlık getiri ile piyasa getirisi karşılaştırılması kullanılmaktadır. Çalışmamızda ilgili şirket verileri bazında her şirketin geçmiş verileri yer almadığından sadece endeks değerleri kullanılacaktır (Benninga, 2008). Olay penceresi (Event Window) basamağında ise ilgili veriler sonrasında 
Kuzu, $S$.

olayın gerçekleşmesi sonrasında, ne kadar süre sonrasında ilgili şirket ya da endeks üzerinde etkisini olacağını göstermektedir. Özellikle bu süre çalışmadan çalışmaya değişmekle birlikte genellikle olaydan sonra beş, on ya da en fazla yirmi günlük süre boyunca ele alınmaktadır. Olay Sonrası Pencere (Postevent Window) basamağında ise olay sonrasında yani kredi derecelendirme kuruluşlarının not bildirimi sonrasında sonraki dönemlerde (ay ya da yıl) etkileri incelenmektedir. İlgili aşamalar Şekil 1'de yer alan Olay Çalışması Yöntemi (Event Study Method) Zaman Çizelgesi ile aşağıda yer almaktadır.

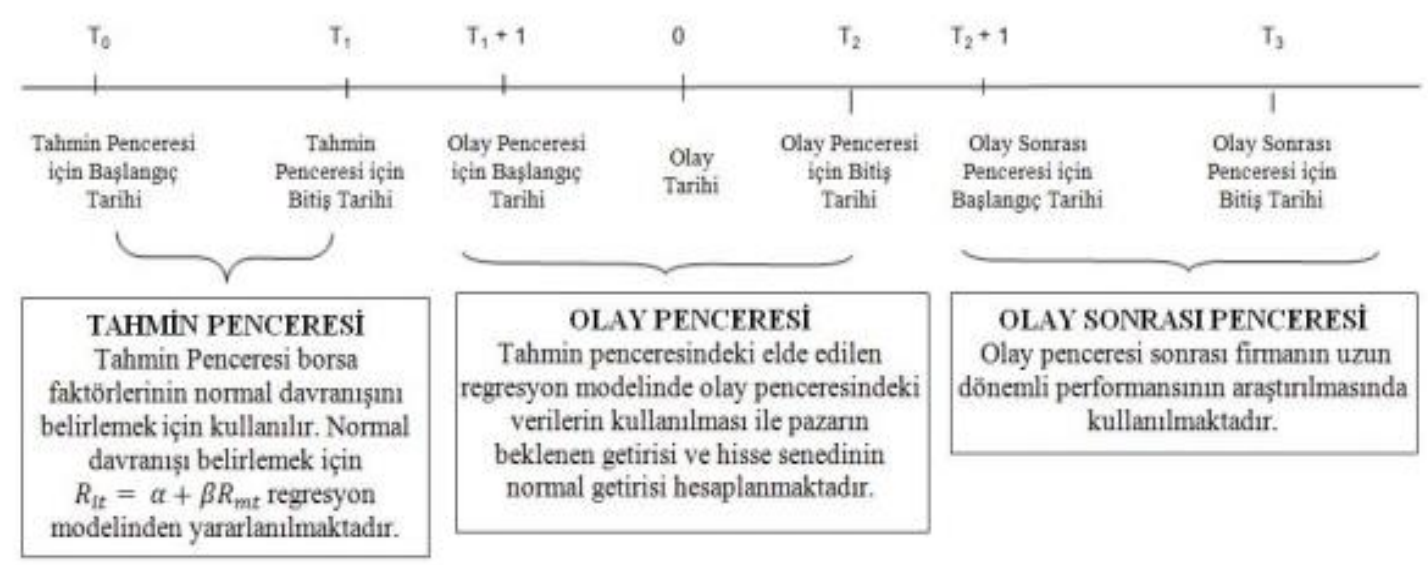

Şekil 1. Olay çalışması yöntemi (event study method) zaman çizelgesi Kaynak: (Benninga, 2008)

Olay Çalışması Metodunda kredi derecelendirme kuruluşlarının not bildirimi esnasında anormal bir getiri yaratıp yaratmadığını ortaya koymaya çalışmaktadır. Anormal getiri beklenen ve gerçekleşen getiri arasındaki farkı ifade etmektedir. Çalışmada anormal getiri hesaplanmasında en çok kullanlan model piyasa modeli olup endeks değeri ile piyasa arasında ki ilişkiyi ortaya koymak amacıyla $\beta$ değerlerinden faydalanılmıştır. Çalışmada anormal getirinin hesaplanmasında ilgili sektörlerin günlük getirileri kullanılmıştır. $\mathrm{Bu}$ getiriler aşağıdaki formülle hesaplanmıştır.

$$
\begin{aligned}
\boldsymbol{R}_{\mathrm{I}, \boldsymbol{t}} & =\left\{\boldsymbol{P}_{\boldsymbol{i}, \boldsymbol{t}-} \boldsymbol{P}_{\boldsymbol{i}(\boldsymbol{t}-\mathbf{1})} \mid \boldsymbol{P}_{\boldsymbol{i}(\boldsymbol{t}-\mathbf{1})}\right\} \\
R_{\mathrm{i}, t} & =\text { endeksin(i), t zamanındaki günlük getirisi } \\
P_{i, t} & =\text { endeksin(i), t zamanındaki kapanış fiyatı } \\
P_{i(t-1)} & =\text { endeksin(i), t zamanındaki bir gün öncesindeki kapanış fiyatı }
\end{aligned}
$$

Çalışmada kullanılacak piyasa modeli için uygulanacak denklem 2'de gösterilmiştir. 


$$
\begin{aligned}
\boldsymbol{E}(\boldsymbol{R})_{\boldsymbol{t}} & =\boldsymbol{\alpha}+\boldsymbol{\beta} \boldsymbol{x} \boldsymbol{R}_{\boldsymbol{m}, t} \\
E(R)_{t} & =\mathrm{t} \text { günündeki beklenen getiriyi } \\
\alpha & =\text { risksiz faiz oranını } \\
\beta & =\text { Beta katsayısı (piyasa getirisinin zaman içindeki eğilimi) } \\
R_{m, t} & =\mathrm{t} \text { gününde piyasa günlük getirisi }
\end{aligned}
$$

Çalı̧̧mada olay penceresini tahmin etmek için kredi derecelendirme kuruluşlarının not açıklamalarından önceki ve sonraki 10 günlük zaman penceresini tahmin edebilmek için, not bildiriminden önceki 250 işlem günü ele alınmıştır. Önceki ve sonraki 10 günü oluşturan 20 günlük işlem anormal getirinin hesaplanması için, ikinci süreci ifade eden 250 işlem günü için piyasa modelinde yer alan $\alpha$ ve $\beta$ katsayıları hesaplanabilme amacıyla kullanılmıştır. $\mathrm{Bu}$ durum her bir sektör açısından ayrı ayrı ele alınmıştır. Her bir sektör için hesaplanan anormal getiriler istatistiki olarak anlamlı olup olmadığı tek örneklemede $t$ testi ile test edilmiştir. Bunun yanında çalışmada her bir derecelendirme kuruluşunun sektör endeksi açısından farklılık yaratıp yaratmadığı irdelenmiştir.

Ortalama anormal getiri, ilgili dönemde yer alan anormal getirilerin aritmetik ortalamasını ele alarak hesaplanmaktadır. Aşağıda yer alan 3'ncü denklemde kümülatif ortalama anormal getiri (Cumulative Average Abnormal Return-CAAR) gösterilmiştir. Kümülatif ortalama anormal getiri olay penceresi kısmında normalin üzerinde gerçekleşen getirilerin ilgili zaman aralığında ki kümülatif toplamı ifade etmektedir.

$$
\operatorname{CAAR}_{i, t}=\sum_{t=0}^{N} A A R_{\mathrm{i}, t}
$$

\section{BULGULAR}

2002-2018 dönemleri arasında kredi derecelendirme kuruluşları arasında en popüler olan üç kuruluştan S\&P, Fitch ve Moody’s Tüekiye için verdikleri not açıklamalarının BIST 100 de yer alan 9 endeks üzerinde not acıkmalarından önceki 10 gün ile not açıklamalarından sonraki 10 günlük olay penceresi üzerinde ortalama anormal getiriler hesaplanmıştır. Analizde 9 endeks üzerinde not açıklamasından sonra getirilerinde olumlu ya da olumsuz sapma olup olmadığı olay çalışması metoduyla ortaya konmaya çalışılmıştır. Bu durum herbir derecelendirme kuruluşu ve sektörler için ayrı ayrı yapılmıştır.

Çalışmada herbir sektör ve kuruluş için yapılan istatistiki uygulamada anormal getiriler ya da 9 endeksin ortalamasın ifade eden ortalama anormal getiriler anlamlı 
Kuzu, $S$.

farklılıklar gösteriyorsa, ilgili not açıklamalarının endeks ya da endeksleri etkilediği ortaya çıkmaktadır. Eğer anormal getiriler pozitif yönde sapma gösteriyorsa not açıklamasının etkisinin pozitif olduğu, tersi durumunda negatif etkisi olduğu söylenebilir. Bunun yanında anormal getiriler ya da ortalama anormal getiriler belirli istatistiki seviyede pozitif yada negatif yönde farklılık oluşturmuyorsa not açıklamalarının endeksler üzerinde etkisinin olmadığını ifade etmektedir.

Kredi derecelendirme kuruluşlarından Moody's, S\&P ve Fitch'in Türkiye için verdikleri not açıklamalarının 10 gün öncesi ve 10 gün sonrasında anormal getiriler, ortalama anormal getiriler ve kümülatif ortalama anormal getiriler dikkat alınarak yapılan istatistiki çalışmaların değerlendirme sonuçları Tablo 5'te yer almaktadır.

Tablo 5. Moody’s, S\&P ve Fitch in 2002-2018 dönemi değerlendirme sonuçları

\begin{tabular}{|c|c|c|c|c|c|c|c|c|c|}
\cline { 2 - 10 } \multicolumn{1}{c|}{} & \multicolumn{3}{c|}{2002} & \multicolumn{3}{c|}{2003} & \multicolumn{3}{c|}{2004} \\
\cline { 2 - 11 } \multicolumn{1}{c|}{} & Moody's & S\&P & Fitch & Moody's & S\&P & Fitch & Moody's & S\&P & Fitch \\
\hline XBANK & {$[2]$} & {$[2,4]$} & $(7),[5]$ & & & {$[6]$} & $X$ & {$[2,5,7,9]$} & $X$ \\
\hline XULAS & {$[1,8]$} & $(2,5)[3,8]$ & & & & & $X$ & & $X$ \\
\hline XMANA & $(2),[7,9]$ & & {$[2,4,6]$} & $(2),[4]$ & $(1),[2]$ & & $X$ & & $X$ \\
\hline XUSIN & {$[5]$} & $(2,8)$ & $(1),[4]$ & & {$[6]$} & & $X$ & {$[4](6)$} & $X$ \\
\hline XUMAL & & & & {$[7,8,10]$} & {$[7,8,10]$} & & $X$ & & $X$ \\
\hline XBLSM & {$[7](3)$} & $(1,5)$ & & & & & $X$ & & $X$ \\
\hline XKOBI & & & $(3),[8]$ & & & {$[4]$} & $X$ & $(2,5,10)$ & $X$ \\
\hline XKMYA & & & & & & & $X$ & & $X$ \\
\hline XMADN & {$[7](1,6,9)$} & & & & $(2,4),[3,7]$ & $(2)$ & $X$ & & $X$ \\
\hline
\end{tabular}

\begin{tabular}{|c|c|c|c|c|c|c|c|c|c|}
\cline { 2 - 11 } \multicolumn{1}{c|}{} & \multicolumn{3}{c|}{2005} & \multicolumn{2}{c|}{2006} & \multicolumn{2}{|c|}{} \\
\cline { 2 - 12 } \multicolumn{1}{c|}{} & Moody's & S\&P & Fitch & Moody's & S\&P & Fitch & & & \\
\hline XBANK & {$[2,5,10]$} & $\mathrm{X}$ & & $\mathrm{X}$ & $(2,7),[8,9]$ & $\mathrm{X}$ & & & \\
\hline XULAS & {$[2,6]$} & $\mathrm{X}$ & & $\mathrm{X}$ & & $\mathrm{X}$ & & & \\
\hline XMANA & & $\mathrm{X}$ & $(2),[8,10]$ & $\mathrm{X}$ & & $\mathrm{X}$ & & & \\
\hline XUSIN & & $\mathrm{X}$ & & $\mathrm{X}$ & $(2),[4,6]$ & $\mathrm{X}$ & & & \\
\hline XUMAL & {$[4](6)$} & $\mathrm{X}$ & & $\mathrm{X}$ & & $\mathrm{X}$ & & & \\
\hline XBLSM & & $\mathrm{X}$ & & $\mathrm{X}$ & & $\mathrm{X}$ & & & \\
\hline XKOBI & & $\mathrm{X}$ & $(7),[2,8,10]$ & $\mathrm{X}$ & $(2),[2,8]$ & $\mathrm{X}$ & & & \\
\hline XKMYA & $(2,9,10)$ & $\mathrm{X}$ & & $\mathrm{X}$ & & $\mathrm{X}$ & & & \\
\hline XMADN & & $\mathrm{X}$ & {$[9](2,5,7)$} & $\mathrm{X}$ & & $\mathrm{X}$ & & & \\
\hline
\end{tabular}




\begin{tabular}{|c|c|c|c|c|c|c|c|c|c|}
\hline & \multicolumn{3}{|c|}{2007} & \multicolumn{3}{|c|}{2008} & \multicolumn{3}{|c|}{2009} \\
\hline & Moody's & $\mathrm{S} \& \mathrm{P}$ & Fitch & Moody's & $\mathrm{S} \& \mathrm{P}$ & Fitch & Moody's & $\mathrm{S} \& \mathrm{P}$ & Fitch \\
\hline XBANK & {$[8,9]$} & {$[2,5,8]$} & & $\mathrm{X}$ & $(5),[7,8,10]$ & $\mathrm{X}$ & $\begin{array}{c}(2,5,7) \\
{[2,5,7,10]}\end{array}$ & $\begin{array}{l}-2,5 \\
{[7,9]}\end{array}$ & $\begin{array}{c}(5) \\
{[2,6,7]}\end{array}$ \\
\hline XULAS & & $(1,3)[4,6]$ & & $\mathrm{X}$ & & $\mathrm{X}$ & & & $(2,8)[4,6]$ \\
\hline XMANA & $(5),[7,10]$ & & & $\mathrm{X}$ & & $\mathrm{X}$ & & (3), $[6,8]$ & \\
\hline XUSIN & $(2),[4,6]$ & & $\begin{array}{l}-2,3 \\
{[4,5]}\end{array}$ & $\mathrm{X}$ & $(3,5,6,9)$ & $\mathrm{X}$ & {$[3,5,7,9]$} & & $(2),[4,6]$ \\
\hline XUMAL & & & (3),[6] & $\mathrm{X}$ & & $\mathrm{X}$ & & [2] & \\
\hline XBLSM & & & & $\mathrm{X}$ & & $\mathrm{X}$ & & {$[1,8]$} & \\
\hline XKOBI & (3), $[6,8]$ & $(2,4)$ & & $X$ & {$[2,9]$} & $X$ & {$[2,7]$} & (2), [7,9] & \\
\hline XKMYA & & & & $\mathrm{X}$ & & $\mathrm{X}$ & & [5] & \\
\hline XMADN & $(2,5,9)$ & $(1,9)$ & $(3,5,9)$ & $\mathrm{X}$ & & $\mathrm{X}$ & & & $(5),[7,9]$ \\
\hline
\end{tabular}

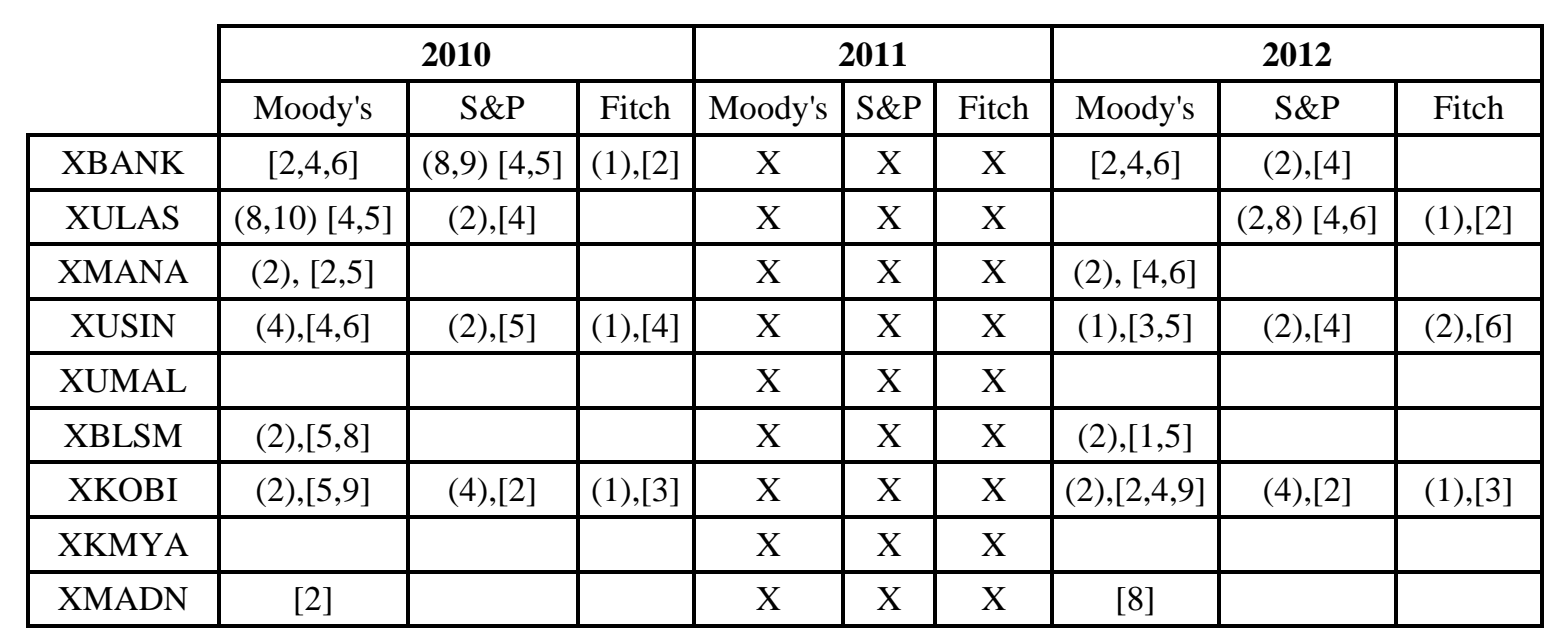

\begin{tabular}{|c|c|c|c|c|c|c|c|c|c|}
\hline & \multicolumn{3}{|c|}{2013} & \multicolumn{3}{|c|}{2014} & \multicolumn{3}{|c|}{2015} \\
\hline & Moody's & S\&P & Fitch & Moody's & $\mathrm{S} \& \mathrm{P}$ & Fitch & Moody's & S\&P & Fitch \\
\hline XBANK & $\begin{array}{c}(2,6,9) \\
{[5,8,10]}\end{array}$ & & & $(2),[3,4]$ & [1](6) & $(1,5),[2,4]$ & $\mathrm{X}$ & $\mathrm{X}$ & \\
\hline XULAS & & {$[2,4]$} & {$[2,7]$} & & & $(3),[4,6]$ & $\mathrm{X}$ & $X$ & [2] \\
\hline XMANA & $(5),[2,5,6]$ & $(2,5)[3,8]$ & & & & & $X$ & $\mathrm{X}$ & {$[1,8]$} \\
\hline XUSIN & & & & & & & $\mathrm{X}$ & $X$ & $(2),[7,9]$ \\
\hline XUMAL & {$[9](2,5,7)$} & $(2,8)$ & & $(2,5),[5,7]$ & & $(2),[2,5]$ & $\mathrm{X}$ & $X$ & \\
\hline XBLSM & $(2,7)[6,8]$ & & & & & & $\mathrm{X}$ & $\mathrm{X}$ & \\
\hline XKOBI & & $(1,5)$ & & {$[10](1,2,5)$} & & $(3),[2,4]$ & $X$ & $X$ & \\
\hline XKMYA & & & & & & & $\mathrm{X}$ & $\mathrm{X}$ & \\
\hline XMADN & {$[2,5,9]$} & & & & & & $\mathrm{X}$ & $\mathrm{X}$ & $(1,5)[6,8]$ \\
\hline
\end{tabular}


Kuzu, $S$.

\begin{tabular}{|l|c|c|c|c|c|c|c|c|c|}
\cline { 2 - 11 } \multicolumn{1}{c|}{} & \multicolumn{3}{c|}{2016} & \multicolumn{3}{c|}{2017} & \multicolumn{3}{c|}{2018} \\
\cline { 2 - 11 } \multicolumn{1}{c|}{} & Moody's & S\&P & Fitch & Moody's & S\&P & Fitch & Moody's & S\&P & Fitch \\
\hline XBANK & {$[2,4,6,8,9]$} & $(2),[4]$ & $(1),[2]$ & $\mathrm{X}$ & $\mathrm{X}$ & $\begin{array}{c}(2,3,4) \\
{[4,5,8,9]}\end{array}$ & $\begin{array}{c}(1,3,6) \\
{[1,2,3,5,8]}\end{array}$ & {$[2,5,7,9]$} & $(7),[2,8,10$ \\
\hline XULAS & $(2,8,10)[4,6]$ & & & $\mathrm{X}$ & $\mathrm{X}$ & $(3),[6,8]$ & {$[9](2,5,7)$} & $\begin{array}{c}(1,2,5) \\
{[4,6]}\end{array}$ & $(2),[6,9]$ \\
\hline XMANA & $(5),[7,9]$ & & & $\mathrm{X}$ & $\mathrm{X}$ & & & & $(1),[3,6]$ \\
\hline XUSIN & $(2),[4,6]$ & $(2),[5]$ & $(1),[4]$ & $\mathrm{X}$ & $\mathrm{X}$ & {$[2]$} & $(1),[2,8]$ & $(3,5)$ & \\
\hline XUMAL & & & & $\mathrm{X}$ & $\mathrm{X}$ & {$[1,8]$} & $(7),[4,6]$ & & \\
\hline XBLSM & $(3),[6,8]$ & & & $\mathrm{X}$ & $\mathrm{X}$ & $\begin{array}{c}(2), \\
{[7,9]}\end{array}$ & & $(1,9)$ & $(2),[6,8]$ \\
\hline XKOBI & $(5),[2,5,9]$ & $(4),[2]$ & $(1),[3]$ & $\mathrm{X}$ & $\mathrm{X}$ & {$[5]$} & $(3,5,9)$ & & \\
\hline XKMYA & & & & $\mathrm{X}$ & $\mathrm{X}$ & & & & $(2,5,9)$ \\
\hline XMADN & {$[2]$} & & & $\mathrm{X}$ & $\mathrm{X}$ & {$[5]$} & $(1,5)[7,9]$ & & \\
\hline
\end{tabular}

Not: ( ) not açıklamadan önceki günü, [ ] not açıklama sonrası günleri ifade etmektedir.

$\% 5$ olasılık düzeyinde istaistiki olarak anlamlı olup olmadığı test edilmiştir.

2002-2018 dönemlerini ele alan kredi derecelendirme kuruluşlarının not açıklamalarının, BIST 100 de yer alan Banka endeksi (XBANK), Ulaşatırma(XULAS), Metal Ana (XMANA), Sınai(XUSIN), Mali(XUMAL), Bilişim(XBLSM), Kobi(XKOBI), Kimya(XKMYA) ve Maden(XMADN) sektörleri üzerinde etkileri not açıklama öncesi 10 gün ve not açıklama sonrası 10 günü ele alacak şekilde ele alınmıştır. $\mathrm{X}$ işaretiyle ifade edilen hücrelerde kredi derecelendirme kuruluşunun ilgili yılda not açıklaması olmadığını ifade etmektedir. Yukarıda Tablo 5 yer alan bilgilere bakıldığında her bir kurumun ilgili sektörler üzerinde not açıklama öncesi yada sonrasında ki anormal getiri yaratan günler yer almaktadır. Yıllar itibarıyla her bir kurumun sektörlere etki ettiği günler farklılık arz etmekte, bazı yıllarda ise herhangi bir etkisinin olmadığı gözlemlenmiştir. Bunun yanında ilgili bazı yıllarda kredi derecelendirme kuruluşlarının not açıklamaları olmadığı için anormal getiri günleri hesaplanamamıştır. Boşta ola hücreler ise kredi derecelendirme kuruluşlarının not açıklamalarının seçili endeks getirileri üzerinde anormal getiriye sahip olmadığı yani endeks getirisi üzerinde herhangi bir etki yaratmadığını göstermektedir.

İstatistiki sonuçlar çerçevesinde kredi derecelendirme kuruluşlarının not açıklamaları sonucunda kümülatif getiri ortalamaları açısında bakıldığında en yüksek sektörün BIST XKMYA endeksinde, en düşük ise BIST XBANK endeksinde görülmüştür.

Genel itibariyle bakıldığında kredi derecelendirme kuruluşlarının not açıklamalarının endeks üzerinde etkisinin hemen hemen \%60 oranında gerçekleştiği gözlemlenmiştir. Bir 
başka ifadeyle kredi derecelendirme kuruluşlarının not açıklamalarının seçili endeksler getirilerinde anormal getiriyi sağladığı görülmüştür.

\section{SONUÇ}

Finansal piyasalarda işlem yapanlar alacakları kararlarda uluslararası kredi derecelendirme kuruluşlarının not kararları büyük önem arz etmektedir. Bunun yanında yatırımcılar yatırım yapmayı düşündükleri ülke ya da işletmelere verilen notlar çerçevesinde aksiyon almaktadırlar. $\mathrm{Bu}$ açıdan bakıldığında uluslararası kredi derecelendirme kuruluşlarının verdikleri not kararlarının hem yatırımcı hem de ülkeler açısından bir referans kaynağı olarak gösterilebilmektedir. Özellikle gelişmekte olan ülkelere yapılan not açıklamaları ülkelerin finansal piyasaları üzerinde ve sermaye girişi, yatırım kararları, cari açık, ithalat ve ihracat, döviz kurları ve enflasyon gibi bir takım makroekonomik parametreler üzerinde etkisi büyük etki yaratmaktadır. Özellikle ülkemiz finansal piyasalarını ele aldığımızda geçmişten günümüze kadar yapılan not açıklamalarının piyasaları önemli ölçüde etkilediği yadsınamaz bir gerçektir. $\mathrm{Bu}$ açıdan uluslararası kredi derecelendirme kuruluşlarının not açıklamalarının ülkemiz hisse senedi piyasaları üzerinde önemli olduğu düşünülen BIST 100 de yer alan dokuz sektör üzerinde etkisinin ortaya konması büyük önem arz etmektedir.

2002-2018 dönemleri arasında kredi derecelendirme kuruluşları arasında en popüler olan üç kuruluştan S\&P, Fitch ve Moody’s Tüekiye için verdikleri not açıklamalarının BIST 100 de yer alan 9 endeks üzerinde not acıkmalarından önceki 10 gün ile not açıklamalarından sonraki 10 günlük olay penceresi üzerinde ortalama anormal getiriler hesaplanmıştır. $\mathrm{Bu}$ endekslerin seçiminde not kararlarından kaynaklı para hareketlerinin en kısa sürede etkisini gösterebilecek endeksler gösterilmiştir. Çalışmada not açıklama öncesi ve sonrasında 10 günlük etkisi analiz açısından ele alınmıştır. Analiz sonuncunda 9 endeks içerisinden yarısından fazlası not açıklamaları duyurularından etkilendiği ve kredi derecelendirme kuruluşlarından pek fazla farklılık arz etmediği görülmüştür.

Çalışma sonucunda uluslararası kredi derecelendirme kuruluşlarının not açıklamalarının BIST 100 de yer alan tüm sektörleri etkilediği ama büyük oranda etkilemediği görülmüştür. Bir başka ifadeyle kredi derecelendirme kuruluşlarının ülkemiz hakkında yaptıkları not açıklamalarının seçili endeksler üzerinde olumlu ya da olumsuz etkisinin belirli oranda kaldığı gözlemlenmiştir. Çalışmamız BIST 100 de yer alan sektörleri hem sektör sayısı 
hem de geniş dönem bazında ele alınması hem olaya daha geniş perspektifte bakılmasına hem de literatüre fayda sağlayacağı düşünülmektedir.

\section{REFERENCES / KAYNAKLAR}

Afonso, A., Gomes, P. \& Philipp, R. (2011). Short and long-run determinants of sovereign debt credit ratings. International Journal of Finance and Economics, 16(1), 3-14.

Alsakka, R. \& Gwilym, O. (2010). Sovereign ratings and migrations: Emerging markets. Bangor Business School Working Paper Financial Studies Division, 1-21.

Benninga, S. (2008). Financial Modelling, (Third Edition). London: The MIT Press.

Cantor, R., \& Packer, F. (1996). Determinants and Impact of Sovereign Ratings. FRBNY Economic Policy Review, 2(2), 37-54.

Fitch. (2019, 2 5). www.fitchratings.com/site/home.

Habib, Y., Nazir, M., Hashmi, S. \& Saeed, M. B. (2016). Credit rating announcements and stock returns: Evidence from the banking sector of Pakistan. Journal of Business Studies Quarterly, 7(2), 61-84.

Haque, N. U., Mark, N. \& Mathieson, D. J. (1998). The relative 1mportance of political and economic variables in creditworthiness. IMF Working Paper, 1-13.

Iltas, Y., Arslan, H. \& Kayhan, T. (2017). The stock return predictability: Comparing P/E and EV/Ebitda. Journal of Economics, Finance and Accounting, 3(4), 262-274.

Juttner, J. \& Carthy, D. (1998). Modeling a ratings crisis. Macquarie University, Sydney, Australia.

Kronwald, C. (2009). Credit Rating and The Impact on Capital Structure. (G. V. Munich, Dü.)

Megginson, W. L., Megginson, D., \& Meggison, W. (1997). Corporate finance theory. Addison- Wesley Inc.

Monfort, B. \& Mulder, C. (2000). Using credit ratings for capital requirements on lending to emerging market economies: Possible impact of a new basel accord. IMF.

Moody's. (2019, 2 5). www.moodys.com.

Mulder, C. \& Perrelli, R. (2001). Foreign currency credit ratings for emerging market economies. IMF Working Paper No. 01/191, 1-22.

Reisen, H. (2003). Ratings since the Asian crisis. OECD Development Centre, Working Paper, 7-9.

S\&P. (2019, 02 05). https://www.standardandpoors.com/en_US/web/guest/home.

SEC. (December 2018). Annual Report on Nationally Recognized Statistical Rating Organizations.

Şensoy, A., Eraslan, V. \& Erturk, M. (2016). Do sovereign rating announcements have an impact on regional stock market co-movements? The case of Central and Eastern Europe. Economic Systems, 40(4), 552-567.

Yıldırım, H. H., Yıldız, C. \& Aydemir, Ö. (2018). Kredi derecelendirme kuruluşlarından S\&P,Moody's ve Fitch'in Türkiye için yapmış oldukları not açıklamalarının hisse senedi endeksleri üzerine etkisi: Borsa İstanbul örneği 2012-2016*. Maliye ve Finans Yazılarl, 9-30.

Yüksel, S. \& Özsarı, M. (2017). Türkiye'nin kredi notunu etkileyen faktörlerin mars yöntemi ile belirlenmesi. Politik Ekonomik Kuram, 16-31. 